
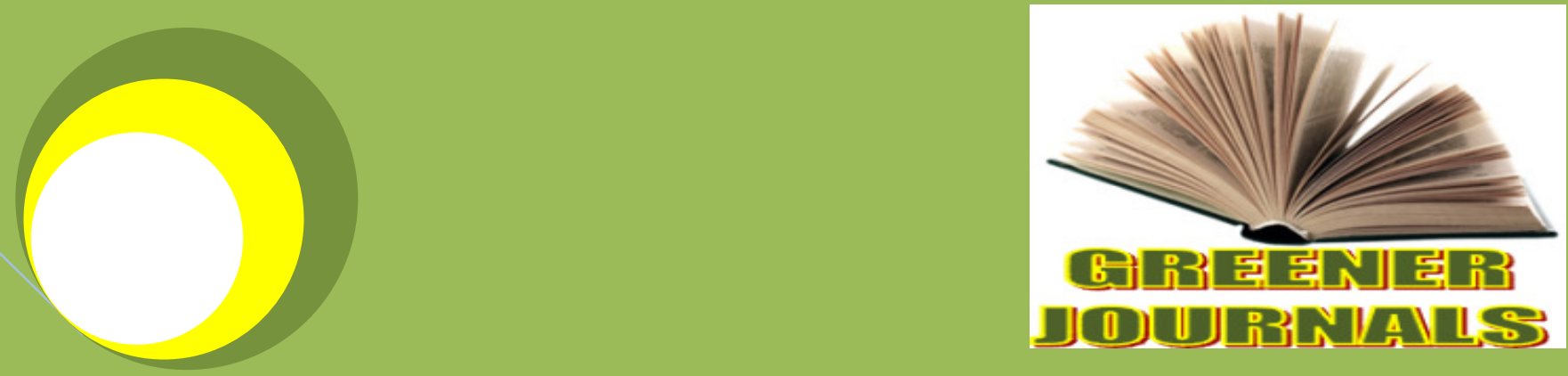

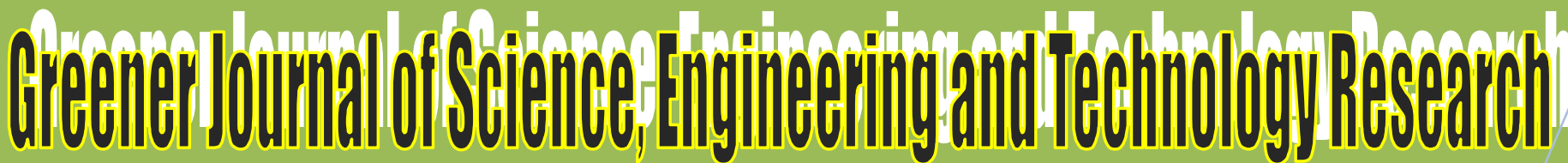
ISSN：2276-7835 Impact Factor 2012 (UJRI): 0.7563 ICV 2012: 5.62

\title{
GIS Based Hydrological Modelling for Climate Change Impact Assessment
}

By

Singh A.

Gosain A. K. 


\title{
GIS Based Hydrological Modelling for Climate Change Impact Assessment
}

\author{
Singh $A .{ }^{* 1}$ and Gosain A. K. ${ }^{2}$
}

\author{
${ }^{1}$ Scientist B, Central Soil and Materials Research Station, Ministry of Water Resources, Government of India. \\ ${ }^{2}$ Professor and Head, Department of Civil Engineering, Indian Institute of Technology Delhi, India. \\ ${ }^{2}$ Email: gosain@civil.iitd.ac.in
}

*Corresponding Author's Email: asingh249@gmail.com, asingh249@rediffmail.com

\begin{abstract}
In the present study, GIS based hydrological modelling has been used to assess the impacts of climate change on the hydrological regime of Cauvery River Basin in India. The hydrological model used for the study is SWAT (Soil and Water Assessment Tool). The analysis has been carried out in three stages. In the first stage, the impact of changes in the land management practices on the water availability in the basin under the present conditions has been modelled. In the second stage, the same analysis has been carried out under the future climatic conditions. The future climate change scenarios have been generated using the daily weather series generated by Hadley Centre, UK (HadRM2). In the third stage, an analysis has been carried out for comparing the annual and monthly precipitation variabilities under the present as well as the futuristic climate change scenarios. The results indicate intensification of the hydrological cycle in the future climate change scenario, which appears to be significant on an annual basis. The study demonstrates that simulation modelling can play a very significant role in conflict resolution by generating a series of scenarios or options for the stakeholders, so as to enable them to take sound rational decisions. Also, implications of climate change on the availability of water in the shared watercourse and consequently, share of each riparian state, can be analysed using modelling techniques.
\end{abstract}

Keywords: Climate change, impact assessment, land management practices, precipitation variability, hydrological modelling.

\section{INTRODUCTION}

In the present study, GIS based hydrological modelling was used to assess the impacts of climate change on the hydrological regime of the Cauvery River Basin in India. The hydrological model used for the study is SWAT (Soil and Water Assessment Tool) (Arnold et al. 1995). SWAT was developed to predict the impact of land management practices on water, sediment and agricultural chemical yields in large complex watershed with varying soils, land use and management conditions over long periods of time. SWAT is a continuous time long-term yield model having the capability of scenario generation so as to equip the policy makers with a wider range of options (Arnold et al., 1995; 1998; Neitsch et al., 2002).

\section{Description of the Study Area}

The Cauvery is the fourth largest river in peninsular southern India, after Godavari, Krishna, and the Mahanadi. The Cauvery rises at an elevation of 1,341m above mean sea-level. In its course of $802 \mathrm{~km}$ from the Western Ghats to the Bay of Bengal, the main river flows for $381 \mathrm{~km}$ in Karnataka, $357 \mathrm{~km}$ in Tamil Nadu, and provides the boundary between the two states for the rest. One of its important tributaries in Karnataka, the Kabini, originates in Kerala; and drainage from Kerala contributes to the Bhavani and the Amaravathy, two of the river's tributaries in Tamil Nadu. Sub-branches of the river irrigate the Karaikal area in Pondicherry before entering the sea. The Cauvery is thus an interstate river, with all four basin states- Karnataka, Tamil Nadu, Kerala, and Pondicherry- having an interest in the sharing of its waters, although Karnataka in the upper and Tamil Nadu in the lower reaches are by far the principal co-riparians. 


\section{Data inputs for Hydrological Modelling}

The SWAT model requires data on terrain, land use, soil, weather and man-made structures like reservoirs for assessment of water resource availability at desired locations of the drainage basin. To create a SWAT dataset, the interface needs to access Arc View map themes and database files, which provide certain types of information about the watershed. The following maps and database files were prepared prior to making the simulation runs:

\section{Contours}

Survey of India topographic sheets on a scale of 1: 250,000 were used. Spatial data was created on the GIS platform using Geomedia Explorer; the polyconic projection system was used. Two line type feature classes were defined, for digitization of contours and stream network. The contours were digitized for the purpose of Digital Elevation Model (DEM) generation and subsequently, watershed delineation.

\section{Stream Network}

Stream network is an optional Arc View map theme which needs to be provided as a shape file. In case it is not provided by the user, the interface generates it using the DEM. In the present case, a polyline shape file of stream network was obtained from the digitized drainage network; this shape file was superimposed on the DEM. The stream delineation shape file was used in the present case because it was felt that in some areas, the relief was so low that the DEM map grid was unable to accurately predict the location of the streams.

\section{Land Use and Soil Class Data}

In case of the land use and soil class data, the user has the option of providing the input data as a shape file or a grid. In the present case, the Cauvery basin land use and soil class data was input as a shape file which was obtained after digitizing the land use maps obtained from the Cauvery authorities on a GIS (Geomedia Explorer) platform. This shape file was later converted into the grid format.

\section{Climatic Data}

The model requires climatic data on precipitation, maximum temperature, minimum temperature, solar radiation, wind speed and relative humidity. Since hydrological processes operate on a continuous basis the variables need to be measured on a sub daily or at least daily basis to accurately predict the hydrological behaviour of the basin. The model has an inbuilt weather generator which can be used for predicting the daily values of all these variables, provided certain long term weather statistics are available. This feature of the model makes it very useful for ungauged watersheds. However, Gholami (1999) has shown that the outputs of the model get closer to the reality if daily observed values are used along with the long term data. The long term (30 year average) data was provided in the User Weather Stations database pertaining to input variables like precipitation, maximum temperature, minimum temperature, solar radiation, wind speed and relative humidity. Recently, Indian Meteorological Department (IMD) has provided the rainfall data for the whole of India considering a grid with a cell size of $1^{\circ} \times 1^{\circ}$ (Rajeevan et al., 2006) and the same was used for the present study. For values of other climatic variables like maximum temperature, minimum temperature and solar radiation, daily values for 3 climatic stations was used along with the long term averages for the same. The daily values of wind speed and relative humidity were simulated by the inbuilt weather generator of the model.

Here it might be mentioned that before the gridded IMD data was made available, the entire analysis was carried out using the long term statistics as well as the daily values for 3 weather stations. The precipitation value obtained on simulating for a 10 year period was about $800 \mathrm{~mm}$. However, after incorporating the additional precipitation data pertaining to daily values of 16 cells from IMD grid, the average 20 year precipitation came out to be about $1000 \mathrm{~mm}$ which is much closer to the actual observed values (913 mm for entire basin up to Musiri for a 10 year period from 1980 to 1989, and $1154 \mathrm{~mm}$ for the entire basin over a 70 year period (CFFC, 1972).

\section{Reservoir Data}

Impoundment structures modify the movement of water in the channel network by lowering the peak flow and volume of flood discharges. A total of nine reservoirs were simulated in the present study. These are Hemavathy, Harangi, KRS, Kabini, Marconahalli, Suvarnavathy, Mettur, Bhavani and Amravathy. These are the major reservoirs in the basin and the data for these was available, that is the reason for their inclusion in the study. All these were input as 
large managed reservoirs with known monthly outflow values. The reservoirs were input on the main channel network after the watershed delineation (described below) is over. Monthly outflow values for all these reservoirs were input as separate tables containing monthly outflow data from the time the reservoir became operational.

\section{Pre-processing}

The following steps were used in pre-processing:

\section{DEM Generation}

The method of interpolation used for the present study is the Inverse Distance Weighted (IDW) method.

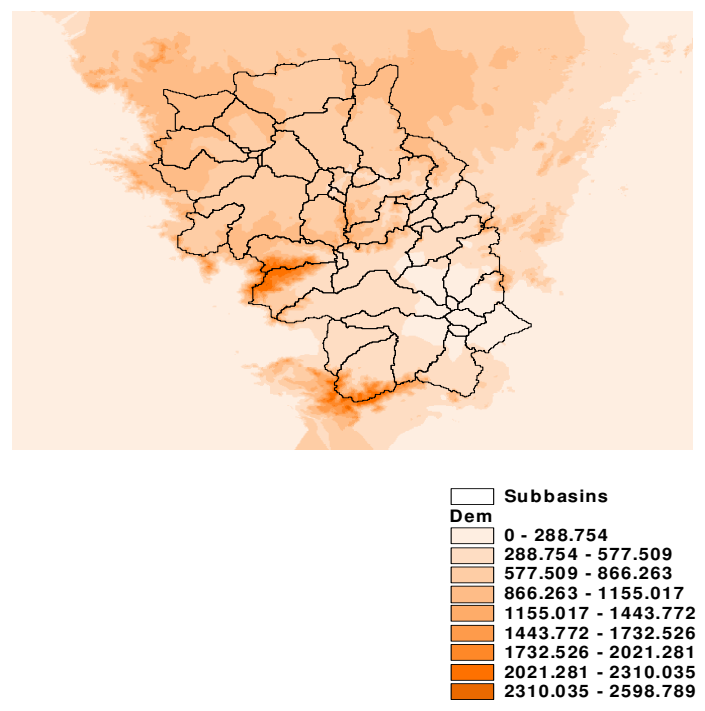

Figure 1 Layout of the Cauvery basin and DEM showing elevations in metres

\section{Watershed Delineation}

Four Grid data matrices that are prerequisite to automatic delineation of watershed in the same sequence are:

- DEM

- Flow Direction

- Flow Accumulation

- Stream Link

\section{HRU Generation}

Each unique combination of land use and soil, class constitutes a "Hydrologic Response Unit" or HRU. Subdividing each sub watershed into unique land use and soil class combinations enables the model to reflect the differences in evapotranspiration and other hydrologic conditions for different land covers/ crops and soils. Runoff is predicted separately for each HRU and routed to obtain the total runoff for the watershed. This increases the accuracy of the water yield predictions and provides a much better physical description of the water balance.

In the present study, the entire basin was subdivided into 42 subbasins. There are two options of determining the HRU distribution. In case a single HRU is to be generated for each subbasin, the HRU is determined by the dominant land use class and soil type within each subbasin. However, in case multiple HRUs are required within each subbasin, a two step procedure is followed. Firstly, land uses are chosen. Once the land uses to be modelled 
are determined, the different soils for each land use are chosen. One HRU is created for each unique land use/ soil class combination. In the present case, since more accuracy is desired, multiple HRUs are chosen within each subbasin. The threshold levels of land use as well as soil types were fixed as $5 \%$. The threshold level is used to eliminate minor land uses/ soil types in each subbasin. In the first stage, land uses that cover a percentage of the subbasin area less than the threshold level are eliminated and the area of the remaining land uses is reapportioned so that $100 \%$ of the land area in the subbasin is modelled. In the second stage, minor soil types within each land use area are eliminated and area of the remaining soil types is reapportioned. After fixing the threshold levels, a total of $231 \mathrm{HRUs}$ were obtained.

\section{Model Calibration}

SWAT has been used extensively throughout the world (Gosain and Rao, 2003). The SWAT model used here had already been calibrated for Kapgari (Behera and Panda, 2006) and Nagwan watersheds (Tripathi et al, 2003; 2004) in India. The daily values of discharges up to Musiri (outlet) were taken from Cauvery basin authorities for the purpose of model validation. The model was validated over a 10 year period from 1980 to 1989 and it was observed that the performance of the model was highly satisfactory. The percentage errors in annual average flows over a 10 year period were estimated as $8.1 \%$ if data from the Central Water Commission (CWC) is used and $10.8 \%$ if data from the Water Resources Development Organisation (WRDO) is used. As a further check, observed and simulated monthly discharges were compared for a two year period and the results were plotted as shown in Figure 4.

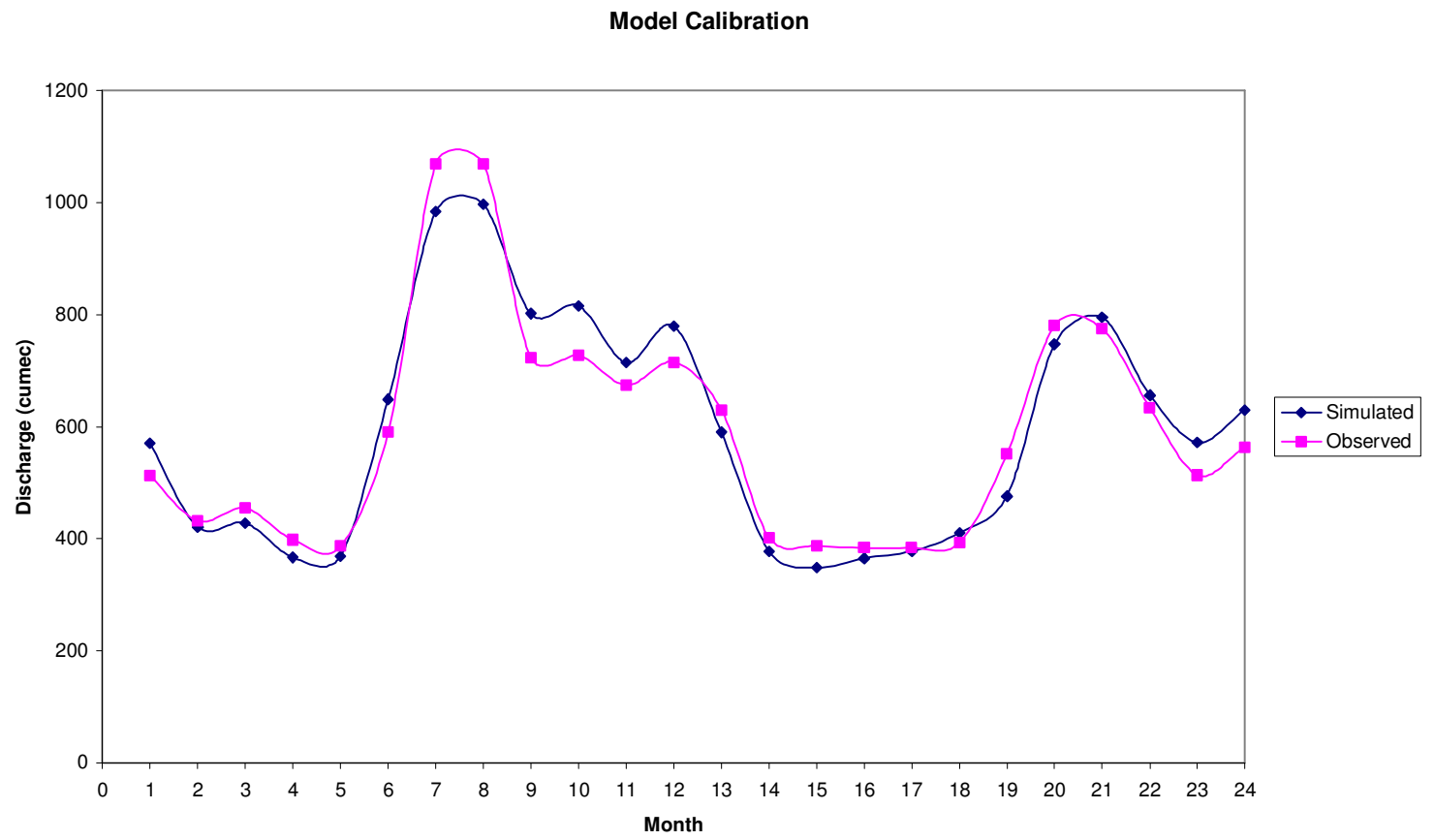

Figure 2 Comparison of average monthly flows over a 2 year period

The Nash Sutcliffe Coefficient was observed to be 0.934 and the value of coefficient of determination was calculated as 0.9362 (Nash and Sutcliffe, 1970). This shows that the model has captured the system well and hence there is no need for further calibration.

\section{Scenario generation using hydrological modelling}

Generation of scenarios is one of the most important applications of hydrological modelling. Scenario generation helps the decision makers to analyse the potential impacts of their actions. In the present case, a variety of land use changes are simulated and the impact on the hydrological characteristics of the basin are analysed. The aim of the exercise is to generate a series of scenarios or options for the stakeholders, so as to enable them to take sound rational decisions. The stakeholders, if they so desire, can use simulation modelling for some other sets of land use changes which are more acceptable to them (Chen, 2003; Luitjen et al., 2003; Rajasekaram et al., 2003). Hence, the 
attempt is to empower the stakeholders by providing them with the freedom of choice. Moreover, the impacts of climate changes on the hydrological regime can be effectively captured through the use of modelling techniques and the remedial actions can be taken well in time. In the current conditions, the (approximate) land uses within the Cauvery basin are:

Agriculture $=60 \%$

Forests $\quad=35 \%$

Others $\quad=5 \%$

Scenarios were generated for three categories of land use changes.

Table 1 shows seven categories of land uses, $S_{1}$ to $S_{7}$ in which $S_{4}$ represents the current conditions:

Table 1 List of Land Use Scenarios

\begin{tabular}{|c|c|c|c|}
\hline $\mathbf{i}$ & Scenario & \%AGRC & \%FRST \\
\hline 1 & $\mathrm{~S}_{1}$ & 75 & 20 \\
\hline 2 & $\mathrm{~S}_{2}$ & 70 & 25 \\
\hline 3 & $\mathrm{~S}_{3}$ & 65 & 30 \\
\hline 4 & $\mathrm{~S}_{4}$ & 60 & 35 \\
\hline 5 & $\mathrm{~S}_{5}$ & 55 & 40 \\
\hline 6 & $\mathrm{~S}_{6}$ & 50 & 45 \\
\hline 7 & $\mathrm{~S}_{7}$ & 45 & 50 \\
\hline
\end{tabular}

Hydrological modelling was carried out on GIS (Arc View) platform to analyse the above mentioned categories of land use changes. The resultant variation of annual water yields of the basin are shown in Figure 3 . Since it is often argued that water allocations should be on the basis of 75 percent dependable flows, the same have also been calculated and plotted in Figure 4. In order to highlight the difference in the water yields under different scenarios, the vertical axes in these figures have the units of TMC (Thousand Million Cubic Feet, $1 \mathrm{TMC}=0.028 \mathrm{cu}$. $\mathrm{km}$.)

Impact of land use changes on water yield

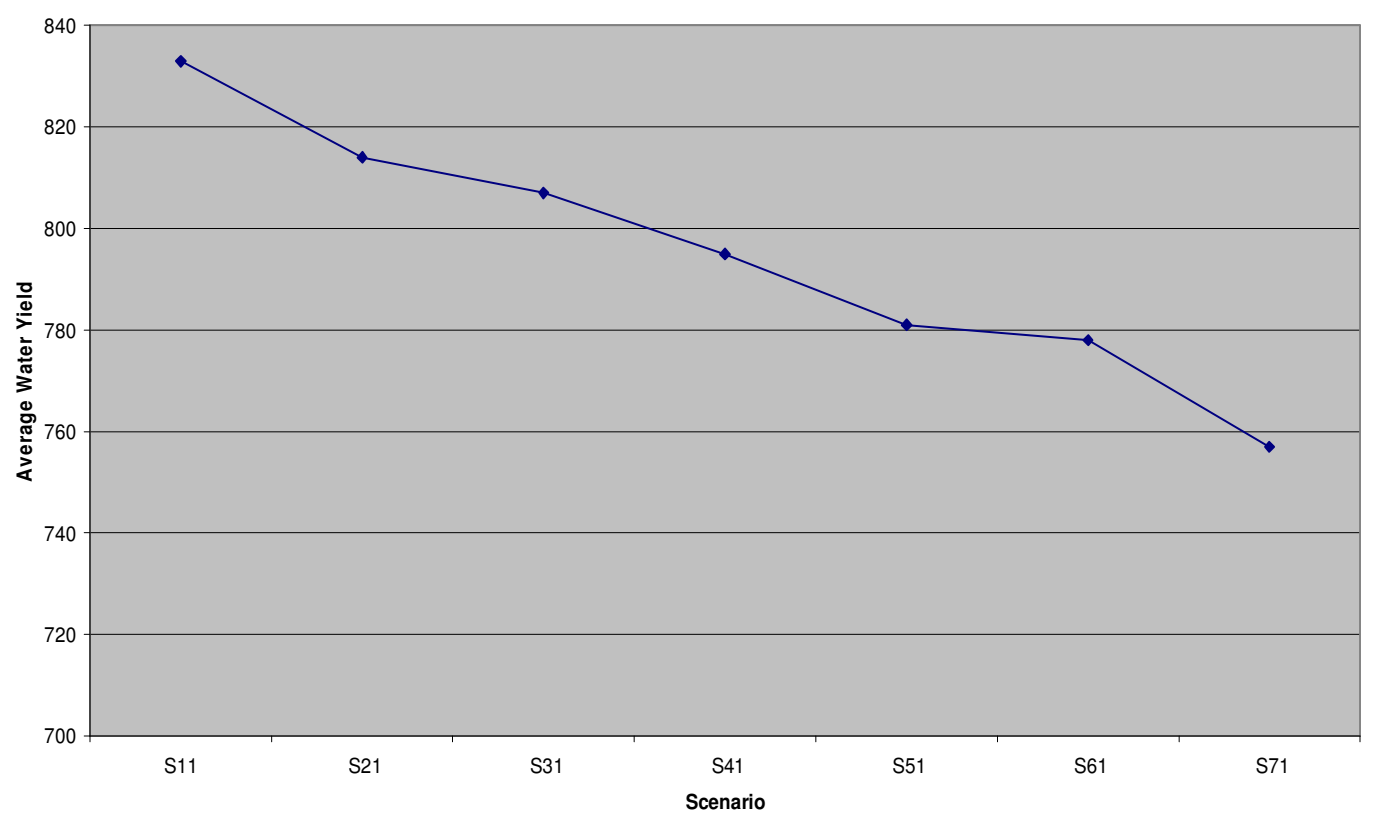

Figure 3 Variation of Average Water Yield in the Cauvery under various land use scenarios. 
Impact of land use changes on water yield

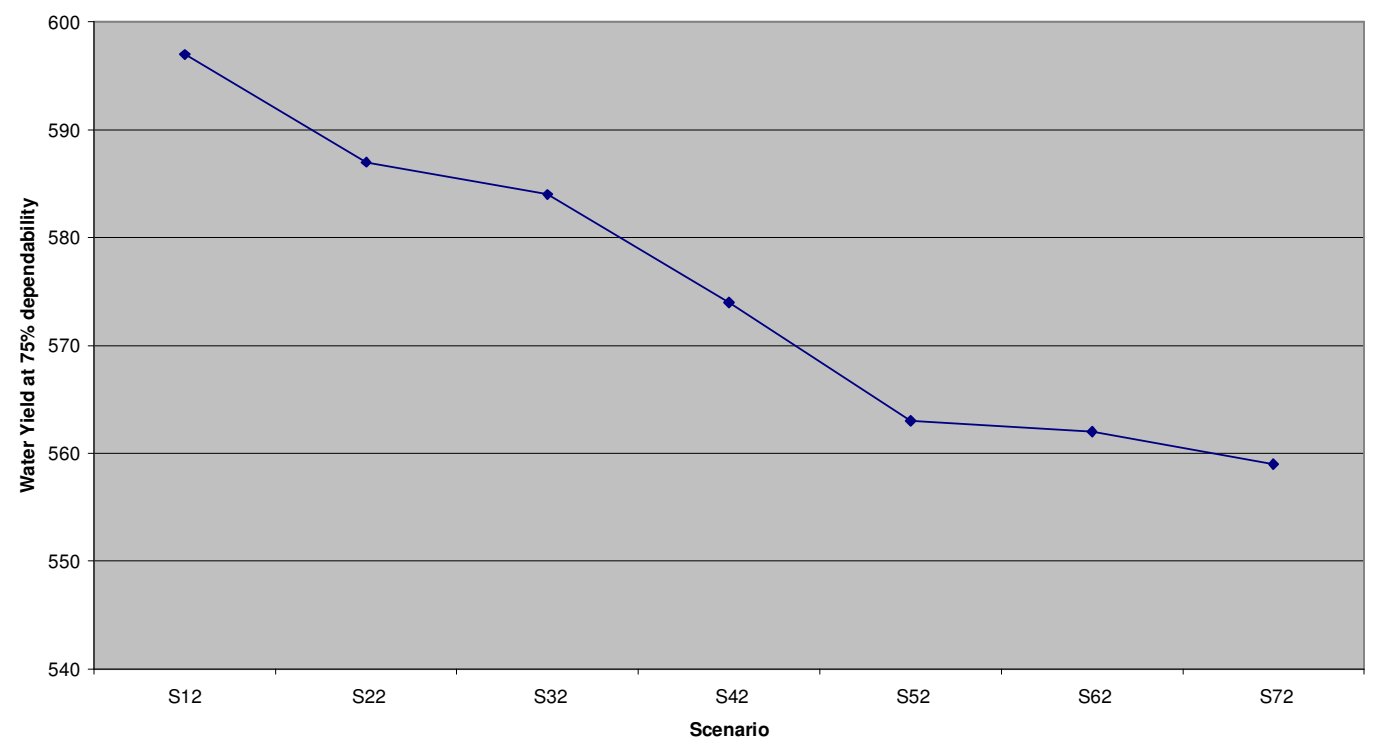

Figure 4 Variation of $75 \%$ Dependable Water Yield in the Cauvery under various land use scenarios

An analysis of the above two graphs shows clearly that as the percentage of forests decreases, the water yield increases in the basin.

The loss of forest cover reduces interception of raindrops (increasing drop impact energy and soil detachment), reduces evapotranspiration, increasing the amount of water available for infiltration, soil storage, and runoff (Hibbert, 1967; Calder et. al, 2009). Therefore, soil moisture capacity is reached with less rainfall, and any excess can produce surface runoff, or Hortonian flow, and increase peak flows and streamflow volumes (Bosch et al. 1982, Moore and Wondzell 2005). Hillbert (1967) reported the results for thirty-nine studies of the effect of altering forest cover on water yield. Taken collectively, these studies reveal that forest reduction increases water yield. Studies have also shown that afforestation (re-establishment of forest cover) results in a decrease in water yield, proportionally to the growth rate of the stand (Hubbart and Matlock 2009).

\section{Scenario generation for Climate Changes}

Climate change challenges existing water resources management practices by adding uncertainty. This adds further complications to the water resources management. (Draper and Kundell, 2007). The data generated in transient experiments by the "Hadley Centre for Climate Prediction" UK, at a resolution of $0.44^{\circ} \times 0.44^{\circ}$ latitude by longitude grid points was obtained from IITM, Pune. The series is known as HadRM2. In order to make predictions, data pertaining to the series was extracted, processed and analysed. This consisted of daily values of precipitation, maximum and minimum temperatures, solar radiation, wind speed and relative humidity for the control as well as future climate change scenarios. The control data for the RM2 series was compared with the actual observations for the present scenario (1970 to 1989). Precipitation was taken as the variable of interest and its mean monthly as well as annual values were compared over a 20 year period. Some of the representative graphs are shown as Figures 5 and 6 . The values of means $(\mu)$ and standard deviations $(\sigma)$ were shown in each graph to compare the variabilities of the two series. Here, it may be mentioned that in some of the graphs below, values of $\mu-\sigma$ and $\mu-2 \sigma$ are negative, and hence they are not shown, since the $Y$ axis contains precipitation values and hence has to truncate at zero. Variability of annual precipitation of the two series is shown in Figures 7 and 8. 


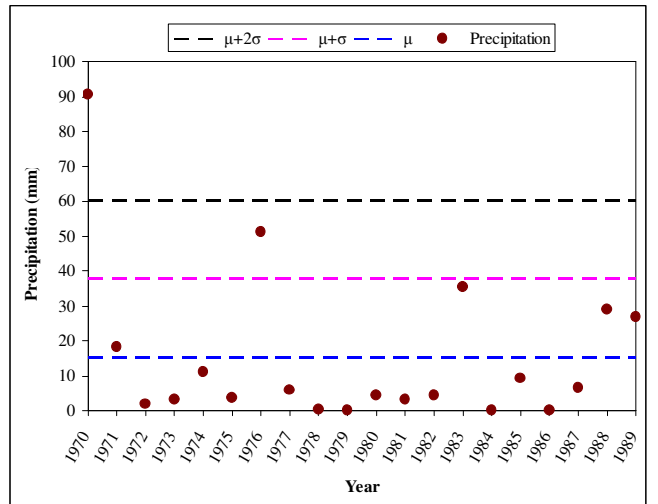

Figure 5 Variability of January precipitation for RM2 control data

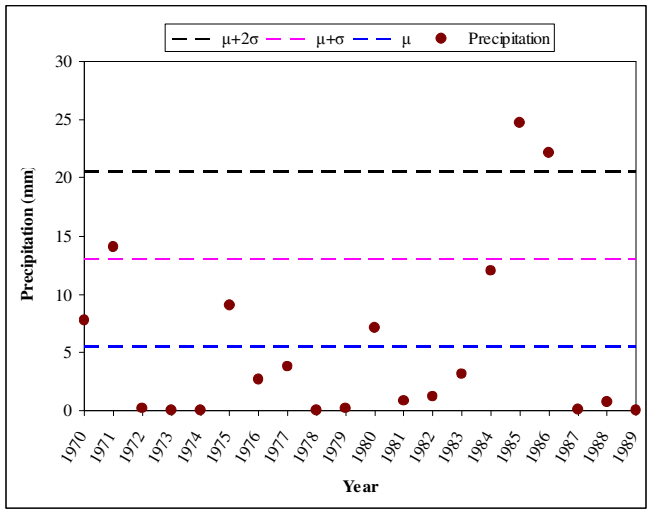

Figure 6 Variability of January precipitation for present data

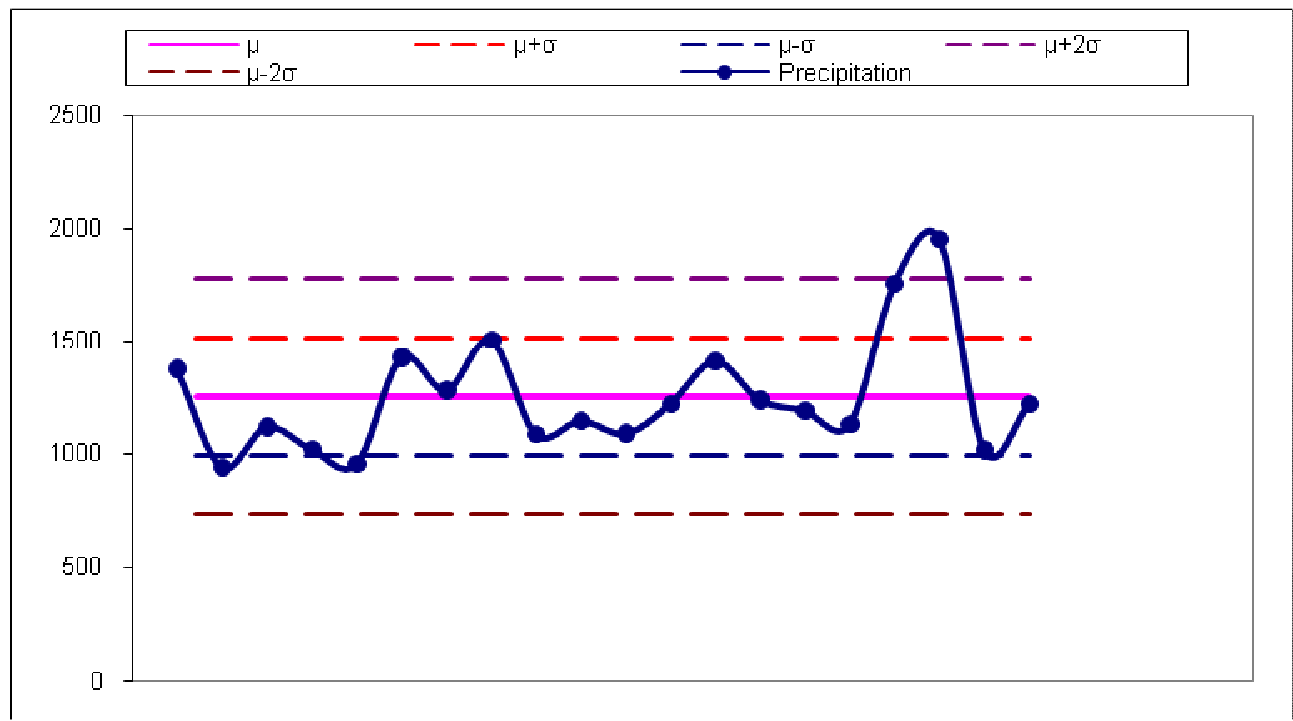

Fig. 7 Variability of Annual Precipitation for RM2 Control Data

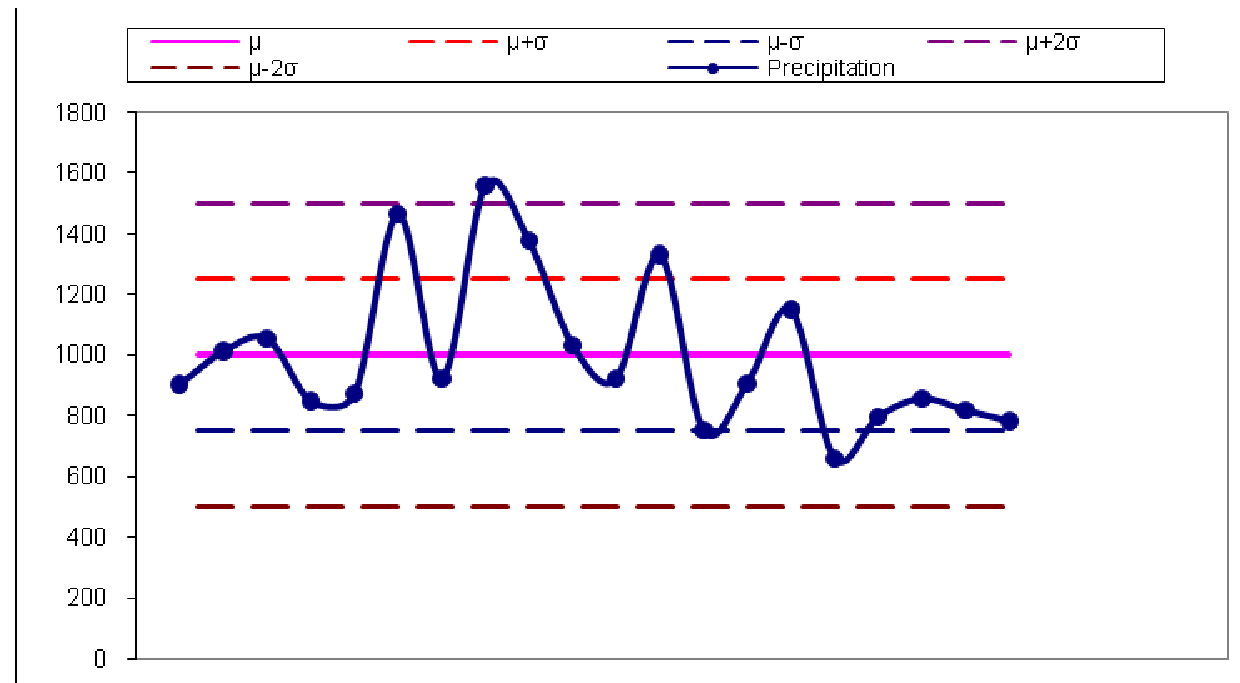

Fig. 8 Variability of Annual Precipitation for Present Data 
The results of these graphs can be summarized as shown in Table 2.

Table 2: Variability of precipitation of RM2 control and present series

\begin{tabular}{|l|c|c|c|c|}
\hline \multirow{2}{*}{ Month } & \multicolumn{2}{c|}{ Actual Present } & \multicolumn{2}{c|}{ RM2 Control } \\
\cline { 2 - 5 } & $\boldsymbol{\mu \pm \boldsymbol { \sigma }}$ & $\boldsymbol{\mu \pm \mathbf { 2 } \boldsymbol { \sigma }}$ & $\boldsymbol{\mu} \mathbf{\boldsymbol { \sigma }}$ & $\boldsymbol{\mu} \mathbf{2 \sigma}$ \\
\hline January & 85 & 90 & 90 & 90 \\
\hline February & 90 & 90 & 80 & 90 \\
\hline March & 90 & 95 & 80 & 95 \\
\hline April & 65 & 95 & 69 & 95 \\
\hline May & 65 & 95 & 75 & 95 \\
\hline June & 75 & 95 & 75 & 95 \\
\hline July & 60 & 100 & 74 & 100 \\
\hline August & 70 & 100 & 74 & 100 \\
\hline September & 65 & 100 & 68 & 100 \\
\hline October & 80 & 95 & 68 & 95 \\
\hline November & 75 & 90 & 90 & 90 \\
\hline December & 75 & 95 & 90 & 95 \\
\hline Annual & 70 & 95 & 80 & 95 \\
\hline
\end{tabular}

Considering the above table, average value of $\mu \pm \sigma$ for present series is 74.23 and that for RM2 control data is 77.92. Similarly, average values of $\mu \pm 2 \sigma$ for present series and RM2 control data come out to be 95 each. Two sample $\mathrm{F}$ test for variances was carried out for the monthly 20 year data for the two series. It showed that variance of present series is 5683.67 whereas that for RM2 control series is 7511.70 . F value comes out to be 0.757 which is less than $\mathrm{F}_{\text {critical }}$ one tail value of 0.81 . Hence, it can be stated that, though RM2 control monthly precipitation series shows more variance than present series, there is no significant difference in the variance of two series.

Two sample $F$ test for variances was also carried out for the annual 20 year data for the two series. It showed that variance of present series is 62554 whereas that for RM2 control series is 67634 . F value comes out to be 0.92 which is more than $F_{\text {critical }}$ one tail value of 0.46 . Hence, it can be stated that RM2 control annual precipitation series shows more variance than present series and the difference is found to be significant using two sample $F$ test for variances.

The future climate change scenarios were generated using the daily weather series generated by Hadley Centre UK (HadRM2). Daily values of precipitation, maximum temperature, minimum temperature, wind speed, relative humidity and solar radiation were obtained for a 20 year period from 2041 to 2060 and the modelling was carried out. The resulting flows along with their comparison with the present actual flows are shown in Table 3.

Table 3: Comparison between present flows and flows with climate change

\begin{tabular}{|c|c|c|c|}
\hline Flows & Scenario & $\begin{array}{c}\text { Present Flows } \\
\text { (cu. km.) }\end{array}$ & $\begin{array}{c}\text { Projected Flows } \\
\text { (cu. . km.) }\end{array}$ \\
\hline Average Flows & $\mathrm{S}_{11}$ & 20.27 & 30.74 \\
\hline Average Flows & $\mathrm{S}_{21}$ & 20.38 & 30.86 \\
\hline Average Flows & $\mathrm{S}_{31}$ & 20.52 & 30.97 \\
\hline Average Flows & $\mathrm{S}_{41}$ & 20.92 & 31.71 \\
\hline 75\% Dependable Flows & $\mathrm{S}_{12}$ & 10.98 & 22.79 \\
\hline 75\% Dependable Flows & $\mathrm{S}_{22}$ & 11.21 & 22.93 \\
\hline 75\% Dependable Flows & $\mathrm{S}_{32}$ & 11.24 & 23.02 \\
\hline 75\% Dependable Flows & $\mathrm{S}_{42}$ & 11.58 & 23.36 \\
\hline
\end{tabular}

Even though Table 3 suggests that there is a very significant increase in flows (for example for $\mathrm{S}_{11}$ case, the increase in flow is more than 50 percent for the climate change scenario), the same may not be taken directly. This is because, as shown earlier, there was a significant difference in the RM2 control data and the present actual data. For example, consider the values of annual precipitation. If we compare RM2 control data with the RM2 data, increase in precipitation is less than $2 \%$. This agrees with the average increase in precipitation between the RM2 control and 
scenario, calculated as a part of NATCOM Project (India's National Communication to the United Nations Framework Convention on Climate Change, UNFCCC) for the Cauvery basin (2.7\%) (Gosain and Rao, 2003). However if we now compare the present actual value $(1000 \mathrm{~mm})$ and RM2 future values (1270), the difference is of the order of $27 \%$. Similarly, in the case of evapotranspiration, if we compare the present actual value and RM2 future values, the difference is about $25.8 \%$.

Hence, it can be stated that the results obtained using the simulated climatic series like RM2 should be used only after verifying them for the area under consideration, which can be done by comparing the control values with the actually observed data.

\section{Variability analysis}

Intergovernmental Panel on Climate Change (IPCC) refers to climate change as a change in the state of the climate that can be identified (using means such as statistical tests) by changes in the mean and/ or the variability of its properties, and that persists for an extended period, typically decades or longer (IPCC, 2008). In the present study, an analysis was carried for comparing monthly precipitation variability precipitation variability under the present as well as the climate change scenarios (along the same lines as done for present actual data and RM2 control data previously). The results of these graphs can be summarized as shown in Table 4.

Table 4: Variability of monthly precipitation of present and climate change scenarios

\begin{tabular}{|l|c|c|c|c|}
\hline \multirow{2}{*}{ Month } & \multicolumn{2}{c|}{ Present } & \multicolumn{2}{c|}{ RM2 Future } \\
\cline { 2 - 5 } & $\boldsymbol{\mu \pm \boldsymbol { \sigma }}$ & $\boldsymbol{\mu} \mathbf{2 \sigma}$ & $\boldsymbol{\mu} \mathbf{\boldsymbol { \sigma }}$ & $\boldsymbol{\mu} \mathbf{2 \sigma}$ \\
\hline January & 80 & 90 & 80 & 90 \\
\hline February & 90 & 90 & 80 & 95 \\
\hline March & 90 & 95 & 75 & 90 \\
\hline April & 65 & 100 & 74 & 100 \\
\hline May & 55 & 95 & 90 & 100 \\
\hline June & 70 & 95 & 80 & 95 \\
\hline July & 64 & 100 & 68 & 95 \\
\hline August & 68 & 100 & 69 & 95 \\
\hline September & 58 & 100 & 63 & 100 \\
\hline October & 80 & 95 & 80 & 95 \\
\hline November & 75 & 90 & 85 & 95 \\
\hline December & 75 & 95 & 95 & 95 \\
\hline
\end{tabular}

Considering the above table, average value of $\mu \pm \sigma$ for present is 72.5 whereas, that for RM2 future is 78.25. Similarly, average values of $\mu \pm 2 \sigma$ for present and RM2 future come out to be 95.42. Two sample $F$ test for variances was carried out for the monthly 20 year data for the two series. It showed that variance of present series is 5683.67 whereas that for future RM2 series is 8354.82 . F value comes out to be 0.68 which is less than $F_{\text {critical }}$ one tail value of 0.81 . Hence, it can be stated that, though RM2 future series shows more variance than present series, there is no significant difference in the variance of two series.

Two sample $F$ test for variances was also carried out for the annual 20 year data for the two series. It showed that variance of present series is 62554 whereas that for RM2 future series is 84184 . F value comes out to be 0.74 which is more than $F_{\text {critical }}$ one tail value of 0.46 . Hence it can be stated that $R M 2$ control annual precipitation series shows more variance than present series and the difference is found to be significant using two sample $F$ test for variances. In other words, intensification of the hydrological cycle can be seen in the future climate change scenario, and it appears to be significant on an annual basis.

\section{CONCLUSIONS}

The results of this exercise indicate that contrary to popular beliefs, as the percentage of forests decreases, water yield increases in the basin. On an annual scale, RM2 control annual precipitation series shows more variance than present series and the difference is found to be significant using two sample $F$ test for variances. The analysis also shows that the results obtained using the simulated climatic series, like RM2 should be used only after verifying them for the area under consideration, which can be done by comparing the control values with the actually observed data. 
Finally, though RM2 future monthly precipitation series shows more variance than present series, there is no significant difference in the variance of two series as determined using two sample $F$ test for variance. However, on an annual scale, RM2 future annual precipitation series shows more variance than present series and the difference is found to be significant using two sample $F$ test for variances. In other words, intensification of the hydrological cycle can be seen in the future climate change scenario, and it appears to be significant on an annual basis. Finally, the study demonstrates that simulation modelling can play a very significant role in conflict resolution by generating a series of scenarios or options for the stakeholders, so as to enable them to take sound rational decisions. Also, implications of climate change on the availability of water in the shared watercourse and consequently, share of each riparian state, can be analysed using modelling techniques.

\section{ACKNOWLEDGEMENTS}

The help provided by Shri Murari Ratnam, Director, Dr. R. Chitra, Scientist 'D' and Shri Manish Gupta, Scientist 'B', Central Soil and Materials Research Station, in carrying out this study is gratefully acknowledged.

\section{REFERENCES}

Arnold, J. G., Williams, J. R., and Maidment, D. R. (1995). "Continuous-time water and sediment-routing model for large basins." Journal of Hydraulic Engineering 121(2):171-183.

Arnold, J. G., Srinivasan, R., Muttiah, R. S., and Williams, J. R. (1998). "Large Area Hydrologic Modeling and Assessment Part I: Model Development." Journal of the American Water Resources Association, 34(1), 73-89.

Behera, S., and Panda, R. K. (2006). "Evaluation of management alternatives for an agricultural watershed in a sub humid sub tropical region using a physical process model. Agric. Ecosys. Environ. 113(1-4), 62-72.

Bosch, J.M. and Hewlett, J.D. (1982). "A review of catchment experiments to determine the effect of vegetation change on water yield and transpiration." Journal of Hydrology, 55, 3-23.

Calder, I. R., T. Nisbet, and J. A. Harrison (2009), "An evaluation of the impacts of energy tree plantations on water resources in the United Kingdom under present and future UKCIP02 climate scenarios." Water Resour. Res., 45, W00A17, doi: 10.1029/2007WR006657.

CFFC (1972). "Report of the Cauvery Fact Finding Committee." Ministry of Irrigation and Power, Government of India, New Delhi.

Draper, S. E., and Kundell, J. E. (2007). "Impact of Climate Change on Transboundary Water Sharing." Journal of Water Resources Planning and Management, 133(5), 405-415.

Gholami, S. A. (1999). "Distributed Watershed Modelling of a Mountainous Catchment" PhD dissertation, Department of Civil Engineering, IIT Delhi.

Gosain, A. K., and Rao, S. (2003). "Impacts of Climate Change on Water Sector." in Shukla, P. R., Sharma, S. K., Ravindranath, N. H., Garg, A., and Bhattacharya, S eds. Climate Change and India: Vulnerability Assessment and Adaptation Universities Press, New Delhi, India.

Gosain, A. K., Rao, S., Srinivasan, R., and Reddy, N. G. (2005). "Return-flow assessment for irrigation command in the Palleru river basin using SWAT model." Hydrological Processes, 19(3), 673-682.

Hibbert, A. R. (1967). "Forest treatment effects on water yield." In: W. E. Sopper and H. W. Lull (Editors), International Symposium for Hydrology. Pergamon, Oxford, 813 pp.

Hubbert, Jason A., and Matlock, M. (2009) "Forest harvest and water yield". In: Encyclopedia of Earth. Eds. Cutler J. Cleveland (Washington, D.C.: Environmental Information Coalition, National Council for Science and the Environment). [First published in the Encyclopedia of Earth October 6, 2009; last revised Date October 6, 2009; Retrieved November 16, 2010.

Neitsch, S. L., Arnold, J. G., Kiniry, J. R., Williams, J. R. and King, K. W. (2002). "Soil and Water Assessment Tool Theoretical Documentation." Version 2000.

Rajeevan, M., Bhate, J., Kale, J. D., and Lal, B. (2006). "High resolution daily gridded rainfall data for the Indian region: Analysis of break and active monsoon spells." Current Science, 91(3), 296-306.

Tripathi, M. P., Panda, R. K., and Raghuwanshi, N. S. (2003). "Identification and Prioritisation of Critical Subwatersheds for Soil Conservation Management using the SWAT Model." Biosystem Engineering, 85(3), 365-379.

Tripathi, M. P., Panda, R. K., Raghuwanshi, N. S., and Singh, R. (2004). "Hydrological Modelling of a Small Watershed using Generated Rainfall in the Soil and Water Assessment Tool Model." Hydrological Processes, 18(10), 1811-1821. 